\title{
Medical Health Simulation Awareness and Opinion among Saudi Commission of Health Specialty Trainees in Saudi Arabia
}

Ahmed H. Ibrahim ${ }^{1 *}$, Meshal Saleh Alduhaim ${ }^{1}$, Maryam T. Tawfik ${ }^{3}$, Shahad Alyousef ${ }^{4}$, Sawsan Alyousef ${ }^{1,2}$

${ }^{1}$ Department Children's Specialized Hospital, King Fahad Medical City, P. O. Box 59046, Riyadh 11525, Saudi Arabia

${ }^{2}$ Department of Postgraduate Simulation Center for Research, Education \& Simulation Enhanced Training (CRESENT), King Fahad Medical City P.O. Box 4911, Riyadh 11412, Saudi Arabia

${ }^{3}$ King Faisal University, P.O. Box 85047 Riyadh 11691, Saudi Arabia

${ }^{4}$ Almaarefa University, P.O. Box 4911, Riyadh 11412, Saudi Arabia

\begin{abstract}
Introduction: Simulation is used to create better and safer environment for the healthcare practitioners and to decrease medical errors. The Saudi Commission for Health Specialties (SCFHS) has introduced multiple simulation courses in few specialties as part of the training curricula for residents and fellows.
\end{abstract}

Objectives: The aim of this study is to assess awareness about medical simulation among SCFHS trainees and identify obstacles that prevent them from participating in such activities.

Methodology: Cross sectional study through electronic survey to residents and fellows under SCFHS from the following regions of Saudi Arabia: Riyadh, Jeddah, Eastern Province, Jizan and Northern Region. Only complete surveys are considered for analysis plus all medical simulation courses except BLS, ACLS, PALS \& ATLS courses.

Result: A total of 313 SCFHS trainees responded to the electronic survey. The majority are 25-30 years of age (65\%). Residents counted for 285 (91\%) (R2=30\% \& R3=22\%) and fellows for 28 (9\%) (F1=2.2\% \& $\mathrm{F} 2=1.6 \%)$. Only 151 out of the 313 participants $(48.2 \%)$ have ever heard of medical simulation, while only 87 (28\%) have ever practiced simulation. The majority of the trainees who are involved in simulation belong to governmental institutes $72(83 \%), 15(17 \%)$ to university institutes and none to private institutes. Around $2 / 3$ of the trainees have simulation centers at their institution. The trainees believe medical simulation should be mandatory in undergraduate and postgraduate training, $83 \%$ and $93 \%$ respectively. The trainees' perceptions about simulation showed (64\%) of them don't know where simulation can be used with a significant P-value of $<0.001$, (9\%). Heard negative experience from others with a significant P-value of $<0.001 \&(>90 \%)$ can improve outcome of patient care, physician skills and medical knowledge with a significant $\mathrm{P}$-value of $<0.001$, $<0.001 \& 0.029$ respectively. The trainees' Perceived Obstacles about simulation showed (67\%) think that Lack of time to attend or create simulation models is an obstacle with a significant P-value of $<0.001 \&(67 \%)$ think that Cost of simulation courses is an obstacle as well with a significant $\mathrm{P}$-value of $<0.001$.

Conclusion: Medical simulation is still not widely practiced in the training of SCFHS trainees in various specialties in Saudi Arabia.

\section{Publication History:}

Received: July 23, 2019

Accepted: September 10, 2019

Published: September 12, 2019

\section{Keywords:}

Medical Health Simulation, Trainees, Saudi Council for Health Specialty, Saudi Arabia

\section{Introduction}

For variety of reasons healthcare education should include advanced technology and innovative methods for optimal training. Simulation based learning has been enthusiastically adopted by healthcare education internationally over the past years. Learning from other professions which successfully established simulated programs in their trainings, such as aviation and space exploration [1]. Simulation is the duplication of a real-life situation, replicating clinical scenarios, in a controlled environment to facilitate learning. As mentioned by The Accreditation Council on Graduate Medical Education (ACGME), stimulation has long been used as a tool to better enhance medical knowledge and practice skills for as early as second year medical students and showed greater importance for post-graduate practice of residents and fellows across the different medical fields. [2,3]. Based on studies, it has a direct effect on the communication skills and team build training of the practitioners as well as building a better and safer environment, facing complex and rare cases [4], assisting in decision making, decreasing medical errors, learning new technologies and procedures that are being introduced frequently [5], and finally having a better understanding of others' professional roles and responsibilities [6]. On the contrary, there are many challenges that could compromise the benefits of this methodology [2]. For instance, understanding the existing types of simulations and choosing the suitable one for each practitioner to fulfill their substantial learning and augment their curriculum $[7,3]$, having cost effective varieties of courses, and accommodating the increasing number of practitioners [3]. The Saudi Commission for Health Specialties (SCFHS) is working on introducing many simulation types as part of the training curriculum to bridge between the literal and practical knowledge.

"Corresponding Author: Dr. Ahmed Hesham Ibrahim, Children's Specialized Hospital, King Fahad Medical City, P. O. Box 59046, Riyadh 11525, Saudi Arabia; E-mail: ahmed.h.ibrahim@hotmail.com

Citation: Ibrahim AH, Alduhaim MS, Tawfik MT, Alyousef S, Alyousef S, et al. (2019) Medical Health Simulation Awareness and Opinion among Saudi Commission of Health Specialty Trainees in Saudi Arabia. Int J Pediatr Neonat Care 5: 158. doi: https://doi.org/10.15344/2455-2364/2019/158

Copyright: (C) 2019 Ibrahim et al. This is an open-access article distributed under the terms of the Creative Commons Attribution License, which permits unrestricted use, distribution, and reproduction in any medium, provided the original author and source are credited. 
Citation: Ibrahim AH, Alduhaim MS, Tawfik MT, Alyousef S, Alyousef S, et al. (2019) Medical Health Simulation Awareness and Opinion among Saudi Commission of Health Specialty Trainees in Saudi Arabia. Int J Pediatr Neonat Care 5: 158. doi: https://doi.org/10.15344/2455-2364/2019/158

Page 2 of 6

\section{Methods}

\section{Study setting and design}

The study was a Cross sectional study that was conducted from January till September 2017 through Google electronic survey.

\section{Study population}

Residents and fellows under Saudi Commission for Health Specialties from the following regions of Saudi Arabia: Riyadh, Jeddah, Eastern Province, Jizan and Northern Region. Only complete surveys are considered for analysis plus all medical simulation courses except BLS, ACLS, PALS \& ATLS courses.

\section{Data collection}

The following data were recorded: Training title and level, trainee nationality, age and specialty, Current institute and city of the institute. Did the trainee hear about medical health simulation (MHS) and have he/she used it before as a learner or as a trainer. Dose the trainee institute have a simulation lab. The trainee perceptions, believes and obstacles about MHS. List five most common simulation courses needed for the trainee's specialty.

\section{Statistical analysis}

Categorical variables such as age group, training title, training level, specialty, etc. were presented in frequencies and percentages. Chisquare / Fisher's exact test was applied according to whether the cell expected frequency is smaller than 5 , and it was used to determine the significant relationship between categorical variables. $\mathrm{P}$ - value < 0.05 two tailed was considered as statistically significant. All data was entered and analyzed through statistical package SPSS 22 (SPSS Inc., Chicago, IL, USA).

\section{Results}

A total number of 313 participants were involved in this study, 285 (91.1\%) residents, mostly were R2 94 (30\%) followed by R3 69 (22\%) while $28(8.9 \%)$ fellows; F1 and $\mathrm{F} 3$ with $2.2 \%$ and $1.6 \%$ respectively. $269(85.9 \%)$ under governmental institutes, 39 (12.5) under universities and $5(1.6 \%)$ under private institutes. Mostly located in Riyadh 172 (55\%), Makkah 50 (16\%), Eastern Province 45 (14.4\%), Asir 19 (16.1\%), Bahrain 3 and finally 1 in Jordan. All under SCFHS training. Responder's majority were specialized in Internal Medicine 48 (15.3), Orthopedic 36 (11.5\%), Pediatric, Obstetrics/Gynecology and General Surgery 28 (8.9\%) for each. Family Medicine 26(8.3\%), ENT 13(4.2\%), Dentistry 12(3.8\%), Emergency Medicine for adults $10(3.2 \%)$ and rest of specialties were less than $3 \%$ (Table 1 ).

Only 151 (48.2\%) of the total participants heard about MHS, and only $87(57.6 \%)$ of them practiced before. 59 (67.8\%) had MHS center at their institute versus $28(32.2 \%)$ who don't have a MHS center in their institute (Figure 1). The majority $39(44.8 \%)$ practiced MHS as learners 1 /year while $23(26.4 \%)$ practiced 2-3 times/year. On the other hand, as a trainer 21 (24.1\%) practiced 1/year and 13 (14.9\%) 2-3 times per year (Table 2). Most common specialties utilizes simulation based simulation are critical care $34.4 \%$, emergency medicine $32 \%$ followed by anesthesia, surgery, internal medicine and obstetrics and gynecology $25.3 \%, 24 \%, 20.6 \%, 16 \%$ respectively. $2.3 \%$ are utilized by orthopedic and administration, least is by pulmonology and

\begin{tabular}{|c|c|c|c|}
\hline & & $\begin{array}{l}\text { No. of } \\
\text { Participants }\end{array}$ & $\%$ \\
\hline \multirow[t]{4}{*}{ Level } & $\mathrm{R} 2$ & 94 & $30 \%$ \\
\hline & R3 & 69 & $22 \%$ \\
\hline & $\mathrm{F} 1$ & 7 & $2.2 \%$ \\
\hline & F3 & 5 & $1.6 \%$ \\
\hline \multirow[t]{3}{*}{ Age } & $<25$ & 25 & $8.0 \%$ \\
\hline & $25-30$ & 205 & $65.5 \%$ \\
\hline & $>30$ & 83 & $26.5 \%$ \\
\hline \multirow[t]{3}{*}{ Institute } & Government & 269 & $85.9 \%$ \\
\hline & University & 39 & $12.5 \%$ \\
\hline & Private & 5 & $1.6 \%$ \\
\hline \multirow[t]{6}{*}{ Region } & Riyadh & 172 & $55 \%$ \\
\hline & Makkah & 50 & $16 \%$ \\
\hline & Eastern Province & 45 & $14.4 \%$ \\
\hline & Asir & 19 & $16.1 \%$ \\
\hline & Bahrain & 3 & \\
\hline & Jordan & 1 & \\
\hline \multirow[t]{10}{*}{ Specialty } & Internal Medicine & 48 & $15.3 \%$ \\
\hline & Orthopedic & 36 & $11.5 \%$ \\
\hline & Pediatric & 28 & $8.9 \%$ \\
\hline & Ob/Gyne & 28 & $8.9 \%$ \\
\hline & General Surgery & 28 & $8.9 \%$ \\
\hline & Family Medicine & 26 & $8.3 \%$ \\
\hline & ENT & 13 & $4.2 \%$ \\
\hline & Dentistry & 12 & $3.8 \%$ \\
\hline & Emergency Medicine (Adults) & 10 & $3.2 \%$ \\
\hline & Rest & & $<3 \%$ \\
\hline
\end{tabular}

Table 1: Demographic Data.

vascular surgery $1.14 \%$ (Table 3). According to the survey 81 (93.1\%) supported MHS being mandatory at residents/fellow programs, and $72(82.8 \%)$ in undergraduate programs compared with $6(6.9 \%)$ who do not support MHS being mandatory in residents/fellow programs and $15(17.2 \%)$ in undergraduate programs with statistical significant $P$ value (Table 4 ). There are 3 main obstacles listed in the survey: first obstacle is related to trainer awareness to MHS, in the opinion of the responders, $64 \%$ related to lack of knowledge where simulation can be applied, $47 \%$ related to lack of knowledge of benefit from simulation, $27.6 \%$ assume simulation is not suitable and $1 \%$ related to limitation of simulation centers. Most of the responders indicated that MHS can improve outcome of patient care, physician skills, medical knowledge and team work with statistical significant $P$ value. Second obstacles related to skills, organizational and technical limitation: in the opinion of the responders, $66.6 \%$ related to lake of time to attend simulation courses, $48 \%$ related to staff skilled in simulation, $47 \%$ related to knowledge on how to create simulation courses and $44.8 \%$ related to lack of equipment. Third obstacles related to cost limitation: in the opinion of the responders, $66.6 \%$ related to high expenses of simulation courses, while $63.2 \%$ related to the expenses of software, hardware and equipment and least $33.3 \%$ related to staff trainers (Table 5). All responders have listed five or more most common simulation courses required at their specialty (Table 6). 
Citation: Ibrahim AH, Alduhaim MS, Tawfik MT, Alyousef S, Alyousef S, et al. (2019) Medical Health Simulation Awareness and Opinion among Saudi Commission of Health Specialty Trainees in Saudi Arabia. Int J Pediatr Neonat Care 5: 158. doi: https://doi.org/10.15344/2455-2364/2019/158

Page 3 of 6

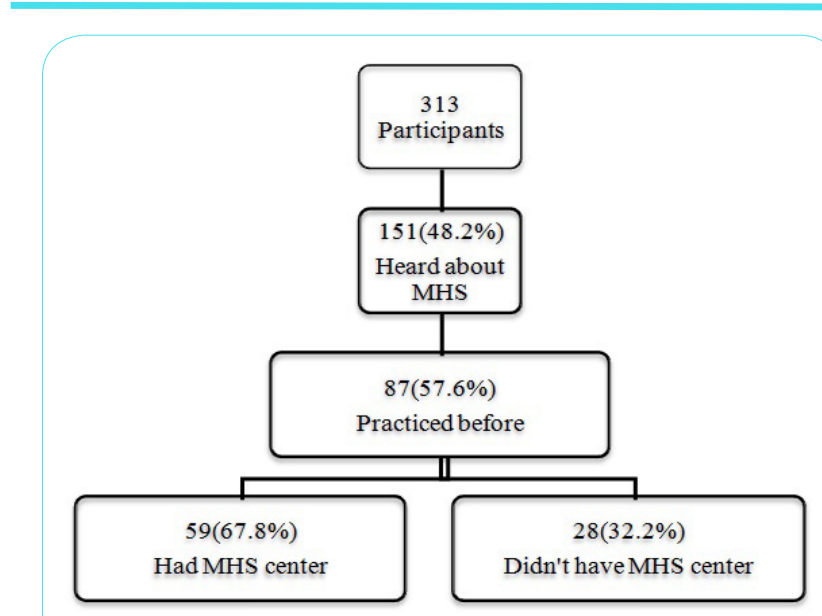

Figure 1: Demonstrated that 313 responders where $48.2 \%$ of them heard about MHS and $57.6 \%$ of them had practiced before and $67.8 \%$ had MHS centers.

\begin{tabular}{|l|l|l|}
\hline & No. of participants who practiced before & $\%$ \\
\hline As a learner & 54 & $62.1 \%$ \\
\hline As a trainer & 16 & $18.4 \%$ \\
\hline As both & 17 & $19.5 \%$ \\
\hline
\end{tabular}

Table 2: previous participation at MHS.

\begin{tabular}{|l|l|l|l|}
\hline \multirow{4}{*}{ Speciality } & Critical Care & 30 & $34.4 \%$ \\
\cline { 2 - 4 } & Emergency Medicine & 28 & $32 \%$ \\
\cline { 2 - 4 } & Anaesthesia & 22 & $25.3 \%$ \\
\cline { 2 - 4 } & Surgery & 21 & $24 \%$ \\
\cline { 2 - 4 } & Internal Medicine & 18 & $20.68 \%$ \\
\cline { 2 - 4 } & Ob/Gyne & 14 & $16 \%$ \\
\cline { 2 - 4 } & Dentistry & 3 & $3.44 \%$ \\
\cline { 2 - 4 } & Administrative & 2 & $2.3 \%$ \\
\cline { 2 - 4 } & Orthopedic & 2 & $2.3 \%$ \\
\cline { 2 - 4 } & Pulmonology & 1 & $1.14 \%$ \\
\cline { 2 - 4 } & Vascular Surgery & 1 & $1.14 \%$ \\
\hline
\end{tabular}

Table 3: Specialties utilizing simulation-based education.

\begin{tabular}{|l|l|l|}
\hline & $\begin{array}{l}\text { Support MHS being } \\
\text { mandatory }\end{array}$ & $\begin{array}{l}\text { Don't support MHS } \\
\text { being mandatory }\end{array}$ \\
\hline Resident/Fellowship & $81(93.1 \%)$ & $6(6.9 \%)$ \\
\hline Undergraduate & $72(82.8 \%)$ & $15(17.2 \%)$ \\
\hline P Value & $<0.001$ & $<0.002$ \\
\hline
\end{tabular}

Table 4: Decision about MHS.

\begin{tabular}{|c|c|c|}
\hline \multicolumn{2}{|l|}{ Obstacle $_{1}$ : Trainer awareness to MHS } & \multirow[t]{6}{*}{ P Value } \\
\hline Lack of knowledge where simulation can be applied & $56(64.4 \%)$ & \\
\hline Lack of knowledge of benefit of simulation & $41(47.1 \%)$ & \\
\hline Assume simulation is not suitable & $24(27.6 \%)$ & \\
\hline Heard of negative experience from others & $8(9 \%)$ & \\
\hline Not encouraged by their superiors and limited simulation centres & $1(1.14 \%)$ & \\
\hline MHS can improve outcome of patient care & $85(97.7 \%)$ & \multirow[t]{2}{*}{$<0.001$} \\
\hline MHS can't improve outcome of patient care & $2(2.3 \%)$ & \\
\hline MHS can improve physician skills & $84(96.6 \%)$ & \multirow[t]{2}{*}{$<0.001$} \\
\hline MHS can't improve physician skills & $3(3.4 \%)$ & \\
\hline MHS can improve physician medical knowledge & $82(94.3 \%)$ & \multirow[t]{2}{*}{$<0.029$} \\
\hline MHS can't improve physician medical knowledge & $5(5.7 \%)$ & \\
\hline MHS can improve team work & $84(96.6 \%)$ & \multirow[t]{2}{*}{$<0.001$} \\
\hline MHS can't improve team work & $3(3.4 \%)$ & \\
\hline Recommend skills simulation courses to be repeated frequently through the year & $83(95.4 \%)$ & \multirow[t]{2}{*}{$<0.006$} \\
\hline Didn't recommend skills simulation courses to be repeated frequently through the year & $4(4.6 \%)$ & \\
\hline \multicolumn{3}{|l|}{ Obstacle $_{2}$ : Obstacles of skills, organizational and technical limitations for the use of MHS } \\
\hline Lack of time to attend or create simulation models & $58(66.6 \%)$ & \\
\hline Lack of staff skills in simulation development & $42(48.3 \%)$ & \\
\hline Lack of knowledge on how to create simulation courses & $41(47.1 \%)$ & \\
\hline Lack of equipment & $39(44.8 \%)$ & \\
\hline Time & $1(1.14 \%)$ & \\
\hline \multicolumn{3}{|l|}{ Obstacle $_{3}:$ Cost limitation of MHS } \\
\hline Simulation courses as main obstacle & $58(66.6 \%)$ & \\
\hline Software, hardware and equipment & $55(63.2 \%)$ & \\
\hline Staff trainers & $29(33.3 \%)$ & \\
\hline
\end{tabular}


Citation: Ibrahim AH, Alduhaim MS, Tawfik MT, Alyousef S, Alyousef S, et al. (2019) Medical Health Simulation Awareness and Opinion among Saudi Commission of Health Specialty Trainees in Saudi Arabia. Int J Pediatr Neonat Care 5: 158. doi: https://doi.org/10.15344/2455-2364/2019/158

Page 4 of 6

\begin{tabular}{|c|c|}
\hline \multicolumn{2}{|c|}{ Five most common simulation courses needed for each speciality listed by the candidates } \\
\hline Speciality & Courses \\
\hline Internal Medicine & Airway management courses \\
\hline Pediatrics & Central line insertion \\
\hline Critical Care & Lumber puncture \\
\hline \multirow[t]{15}{*}{ Emergency Medicine } & Management of crisis/arrest/code \\
\hline & Chest tube insertion/pleural tapping \\
\hline & Mechanical ventilation courses \\
\hline & Medical scenarios \\
\hline & Bronchoscope \\
\hline & Basics of ultrasound \\
\hline & Ascitic fluid tapping \\
\hline & Cardiac simulation courses \\
\hline & Rapid response team \\
\hline & ABG procedure \\
\hline & Folly's catheter insertion \\
\hline & Communication \\
\hline & Toxicology \\
\hline & Disaster \\
\hline & CRRT \\
\hline \multirow[t]{14}{*}{ Obstetrics /Gynaecology } & Basic surgical skills \\
\hline & BOSS \\
\hline & ALSO \\
\hline & Postpartum hemorrhage \\
\hline & Eclampsia \\
\hline & Antepartum haemorrhage \\
\hline & Laparoscopy \\
\hline & Shoulder dystocia \\
\hline & Instrumental delivery \\
\hline & Crowdedness in labour ward \\
\hline & OBERT \\
\hline & Cord prolapse \\
\hline & Fetal bradycardia \\
\hline & Maternal collapse \\
\hline \multirow[t]{5}{*}{ Family Medicine } & Basics of Ultrasound \\
\hline & Clinical examination \\
\hline & Identification of heart murmurs \\
\hline & Basic surgical skills \\
\hline & Lumber puncture \\
\hline \multirow[t]{5}{*}{ Surgery } & Basic surgical skills \\
\hline & BOSS \\
\hline & Laparotomy and laparoscopy \\
\hline & Abdominal wall surgery and hernia repair \\
\hline & FAST \\
\hline \multirow[t]{2}{*}{ Anaesthesia } & Airway management \\
\hline & Central line insertion \\
\hline
\end{tabular}


Citation: Ibrahim AH, Alduhaim MS, Tawfik MT, Alyousef S, Alyousef S, et al. (2019) Medical Health Simulation Awareness and Opinion among Saudi Commission of Health Specialty Trainees in Saudi Arabia. Int J Pediatr Neonat Care 5: 158. doi: https://doi.org/10.15344/2455-2364/2019/158

Page 5 of 6

\begin{tabular}{|c|c|}
\hline & Lumbar puncture \\
\hline & Obstetric anaesthesia \\
\hline & Regional anaesthesia \\
\hline & Hemodynamic monitoring \\
\hline & Management of crises/arrest/code \\
\hline \multirow[t]{4}{*}{ Ophthalmology } & Phacoemulsification \\
\hline & Corneal suture \\
\hline & Refractory surgery \\
\hline & Vitrectomy \\
\hline \multirow[t]{8}{*}{ Orthopaedic } & Arthroscopy/Arthroplasty \\
\hline & Inserting IM nailing \\
\hline & Cast manoeuvre \\
\hline & Management of open fracture \\
\hline & Close reduction of dislocation \\
\hline & AO basics and advance \\
\hline & Basic surgical skills \\
\hline & BOSS \\
\hline \multirow[t]{7}{*}{ ENT } & Paranasal sinuses surgery \\
\hline & Thyroid surgery \\
\hline & Neck dissection \\
\hline & Laryngoscope \\
\hline & Temporal bone dissection \\
\hline & Laser laryngoscope \\
\hline & Bronchoscope \\
\hline
\end{tabular}

Table 6: Five most common simulation courses needed for each specialty listed by the candidates.

\section{Discussion}

The practice of medicine has been a growing field throughout the decades. Many modalities have been used to expand the training of residents and fellows across different specialties [1]. Simulator use that mimics a real-life situation has been one of the leading modalities in the field of medical education [3]. Not only does it help the trainees to build a strong problem-solving base, but it also strengthens their teamwork capabilities [2]. One of the main assets of simulation-based learning is to focus mainly on hand on practice rather than didactic lecturing. For that, the trainee needs to have previous theoretical knowledge on the subject itself [8]. Having simulation-based learning as part of the medical education throughout the trainees' journey amplifies many qualities. For example, the trainee will be more involved in the decision making rather than purely receiving the information as it is, which will have a direct impact on building his/ her character in dealing with real life situations [7]. All the levels of medical education should have simulation as an integral part of its program. That is due to the growing impact it has on enhancing the practitioner's problem solving in clinical situations, introducing new technologies aiding with diagnosis and management, and limiting the rate of medical errors [9]. Studies have shown that high fidelity medical simulation has a direct impact on the skill of avoiding harmful actions by continues training and repetition and an effect on marked progress of the trainees $[10,11]$. Other studies have shown that simulation practice had a vivid impact on medical students as well, when used early on in their practice. It helped them understand the basics of hands on practice and the crucially of teamwork in the medical field. It also helped them narrow down their interests in which kind of specialty they would like to pursue their career [6]. In order to reach the highest level of effectiveness and ensure benefit, several conditions need to be met. Starting from sharing comments to learners, providing opportunities with ongoing engagement in practice, integrating the curriculum, deliberating practice leveling the difficulty to equalize the practitioners' ability, and having a controlled environment that practitioners can detect and pick patient care errors $[1,9,12,18]$. There are many ways to make the simulation more appealing to the trainees. One of the theories that could be used is the gamification. Relatedness, autonomy, and internalized motivation are goals achieved by participating in different learning modalities such as gamification [13]. There are different types of simulators to fulfill the needs of each program. For example, human patient, task trainers, standardized patients and virtual reality [12]. Another type of simulation is the hybrid combined encounter, which is having a standardized patient to take history from then preform a physical examination or a procedure on a mannequin that increases the trainees' capability of preforming some physical skills and increasing his/her communication skills [15]. Moreover, some simulations on cadavers had shown a high reported benefit compared to other non-cadaveric simulation [16]. In our study, we encountered 313 participants most of them worked in governmental hospitals and universities, almost half of them 151 (48.2\%) heard about MHS, and only 87 (57.6\%) practiced in it before (figure 1). Those who practiced mentioned that having an MHS centre at their hospital helped them a lot. Especially with the large number of graduates from medical schools, the opportunity of practicing fundamental skills during their school training decreased. 
Citation: Ibrahim AH, Alduhaim MS, Tawfik MT, Alyousef S, Alyousef S, et al. (2019) Medical Health Simulation Awareness and Opinion among Saudi Commission of Health Specialty Trainees in Saudi Arabia. Int J Pediatr Neonat Care 5: 158. doi: https://doi.org/10.15344/2455-2364/2019/158

Page 6 of 6

Our data shows that critical care (34.4\%) and emergency medicine $(32 \%)$ where the highest specialties who utilized simulation-based education (Table 3). With most courses in MHS designed for their needs (such as intubation, mechanical ventilation, interosseous (IO), central line, lumbar puncture (LP), etc...). The participants have listed the most desired workshops per specialty that they would be most interested in attending. Those workshops would help them build a stronger data base to enrich their knowledge [3].another study conducted on pediatric residents at all levels, supported the efficacy of pediatric airway simulation courses which proved junior residents to score in knowledge and practical skills as high as senior residents at the end of the course [18]. From the 87 participants who practiced MHS 81 (93\%) support that it should be mandatory at residents/ fellow programs, and $72(82.8 \%)$ in undergraduate programs and that implies the importance of MHs training (Table 4). Based on the updates in each field, some courses will need to be retaken every other year or so to ensure enough procedures are done to achieve competency [18].Other studies proved the retention of both knowledge and clinical skills post simulation courses for pediatric R1 trainees [19]. Some of the obstacles encountered in our study were due to the lack of centers offering simulation workshops, as well as the limited knowledge by the trainees on where, how and when to apply The lack of workshops in centers is secondary to either lack of skilled staff for training or limited equipment [20]. 66.6\% of the participants found that the workload and the tight schedule are main withdrawers. Moreover, the benefits of participating in simulation workshops are not highly encouraged by seniors (Table 5 ).

\section{Conclusion}

Medical simulation is still not widely practiced in the training of SCFHS trainees in various specialties mainly because of limited awareness about such training modalities plus limited resources. Will share our data with SCFHS stake holder to introduce medical simulation courses into the curriculum of all specialties in Saudi Arabia.

\section{Ethics Approval}

The research was approved by IRB Committee at King Fahad Medical City (IRB 16-145)

\section{Acknowledgment}

Salman Bashir, Department of Biostatics, King Fahad Medical City.

\section{Authors' Contributions}

Study conception and design: SA. Alyousef, Ahmed H. Ibrahim Acquisition of data: Ahmed H. Ibrahim, M. Alduhaim

Analysis and interpretation of data: Ahmed H. Ibrahim, M. Alduhaim, $\mathrm{SH}$. Alyousef and M. Tawfik

Drafting of manuscript: Ahmed H. Ibrahim, M. Tawfik, SH. Alyousef and SA. Alyousef

Critical revision: SA.Alyousef, Ahmed H. Ibrahim

\section{Competing Interests}

The authors declare that they have no competing interests.

\section{References}

1. Motola I, Devine LA, Chung HS, Sullivan JE, Issenberg SB, et al. (2013) Simulation in healthcare education: A best evidence practical guide. AMEE Guide No. 82. Med Teach 35: 1511-1530.

2. Edwards CL, Johnson S (2005) Revisiting Residency Training: A Book Review Revisiting Residency Training: A Book Review. PsycCRITIQUES.

3. Lopreiato JO, Sawyer T (2015) Simulation-Based Medical Education in Pediatrics. Acad Pediatr 15: 134-142.

4. Hamstra S, Philibert I (2012) Simulation in Graduate Medical Education: Understanding Uses and Maximizing Benefits. J Grad Med Educ 4: 539-540.

5. Lababidi $\mathrm{H}$, Munshi $\mathrm{F}$ (2015) Development of simulation curriculum in postgraduate programs. Journal of Health Specialties 3: 17.

6. Lopreiato JO, Sawyer T (2015) Simulation-Based Medical Education in Pediatrics. Acad Pediatr 15: 134-142.

7. Lopreiato JO, Sawyer T (2015) Simulation-Based Medical Education in Pediatrics. Acad Pediatr 15: 134-142.

8. Rudolph JW, Raemer DB, Simon R (2014) Establishing a safe container for learning in simulation: the role of the presimulation briefing. Simul Healthc 9: 339-349.

9. Issenberg SB, Mcgaghie WC, Petrusa ER, Gordon DL, Scalese RJ, et al. (2005) Features and uses of high-fidelity medical simulations that lead to effective learning: A BEME systematic review. Med Teach 27: 10-28.

10. Sudikoff SN, Overly FL, Shapiro MJ (2009) High-Fidelity Medical Simulation as a Technique to Improve Pediatric Residents Emergency Airway Management and Teamwork. Pediatr Emerg Care 25: 651-656.

11. Lous ML, Chanaud ND, Bourret A, Senat MV, Colmant C, et al. (2017) Improving the quality of transvaginal ultrasound scan by simulation training for general practice residents. Adv Simul (Lond) 2: 24

12. Lopreiato JO, Sawyer T (2015) Simulation-Based Medical Education in Pediatrics. Acad Pediatr 15: 134-142.

13. Rutledge C, Walsh CM, Swinger N, Auerbach M, Castro D, et al. (2018) Gamification in Action: Theoretical and Practical Considerations for Medical Educators. Acad Med 93: 1014-1020.

14. Hamstra S, Philibert I (2012) Simulation in Graduate Medical Education: Understanding Uses and Maximizing Benefits. J Grad Med Educ 4: 539-540.

15. Seo J, Oh Y, Im S, Kim D, Kong H, et al. (2018) Authenticity, acceptability, and feasibility of a hybrid gynecology station for the Papanicolaou test as part of a clinical skills examination in Korea. J Educ Eval Health Prof 15: 4.

16. Gasco J, Holbrook TJ, Patel A, Smith A, Paulson D, et al. (2013) Neurosurgery Simulation in Residency Training: Feasibility, Cost, and Educational Benefit. Neurosurgery 1: 39-45.

17. Alyousef S, Marwa H, Alnojaidi N, Lababidi H, Bashir MS, et al. (2017) Cumulative evaluation data: Pediatric airway management simulation courses for pediatric residents. Advances in Simulation.

18. Flannery MT, Zahorsky S (2014) Simulation in Residency Training: A Review. Creative Education 5: 31-36.

19. Alyousef SA, Marwa H, Alnojaidi N, Lababidi H, Bashir MS, et al. (2018) Cumulative Evaluation Data: Simulation Based Learning Courses for Pediatric R1 Residents. Journal of pediatric and neonatal Biology.

20. Kirchhof P, Meseth N (2012) A survey on the use of simulation in German healthcare. Proceedings Title: Proceedings of the 2012 Winter Simulation Conference. 